\title{
Feeling the Doctorate: Is Doctoral Research that Studies the Emotional Labor of Doctoral Students Possible?
}

\author{
Liora Nutov and Orit Hazzan \\ Department of Education in Technology and Science, \\ Technion - Israel Institute of Technology, Haifa, Israel \\ lorano@bezeqint.net; oritha@techunix.technion.ac.il
}

\begin{abstract}
This paper addresses the emotional labor of qualitative researchers in the social sciences, in general, and of doctoral students in the social sciences whose research is conducted using the qualitative research paradigm, in particular. The first part of this paper presents a brief review of the literature on the emotional labor of researchers in the social sciences. The second part of this paper discusses a doctoral research that investigates the emotional labor of doctoral students, examining two questions: First, why is it important to study the emotional labor of doctoral students? And second, can the topic "The emotional labor of doctoral students while conducting their doctoral research" in itself constitute a topic for a doctoral dissertation?
\end{abstract}

Keywords: Emotional Labor; Social Sciences; Doctoral Dissertation; Doctoral Studies.

\section{Introduction}

Our interest in the topic of the emotions of researchers conducting qualitative research in general, and the emotions of doctoral students conducting qualitative research in the social sciences in particular, was sparked following an emotional turmoil experienced by the first author while conducting her doctoral research under the supervision of the second author. An analysis of the reasons that led to this emotional turmoil and of her attempt to cope with it, led us to expand the topic of the researcher's emotions while conducting research into a broader discussion. In this paper, we will present this discussion by examining the ways in which doctoral students manage their emotions while conducting their doctoral research, focusing on those conducting qualitative research. In particular, we will discuss two questions in this context:

- Why is it important to study the emotional labor of doctoral students?

- Can the topic "The emotional labor of doctoral students" constitute in itself a topic for a doctoral dissertation?

Material published as part of this publication, either on-line or in print, is copyrighted by the Informing Science Institute. Permission to make digital or paper copy of part or all of these works for personal or classroom use is granted without fee provided that the copies are not made or distributed for profit or commercial advantage AND that copies 1) bear this notice in full and 2) give the full citation on the first page. It is permissible to abstract these works so long as credit is given. To copy in all other cases or to republish or to post on a server or to redistribute to lists requires specific permission and payment of a fee. Contact Publisher@InformingScience.org to request redistribution permission.

The discussion of these questions is important in light of a more general question - Can the emotional involvement of researchers have a detrimental effect on research? - and also in light of the two existing approaches that differ in their answer to this question. On the one hand, the traditional viewpoint, based on the standpoint voiced by the 17 th century philosopher René Descartes, who de- 
clared "I think, therefore I am" (Keegan, 2006), lauds the disassociation between cognition and emotion and instructs researchers to maintain objectivity and emotional disconnection from the topic of research so as to reveal the truth. On the other hand, a feminist viewpoint in research holds that the emotional labor that researchers perform should be acknowledged, some even calling for the recognition of researchers' emotions as additional research data (Blee, 1998; Coffey, 1999; Gilbert, 2001; Haynes, 2006). Clearly, other approaches exist as well.

In this paper, we will first review the literature on emotional labor in qualitative research, and then we will focus on a doctoral research that investigates the emotional labor of doctoral students. We note that this paper is neither a research paper nor a comprehensive literature review on doctoral studies; other resources which are dedicated to these topics are available (e.g., Atkinson, Delamont, \& Parry, 2000). In writing this paper we intend to increase the awareness of the emotional work of doctoral students in the context of qualitative research.

\section{Emotional Labor While Conducting Qualitative Research}

When conducting qualitative research, it is customary to emphasize that researchers must be aware of the emotions of the research participants, and the need to protect the research participants from any emotional harm is highlighted (Lucas \& Lidstone, 2000). To that end, various research bodies and government agencies, including universities, have adopted ethical codes. At the same time, researchers report on a variety of emotions that they themselves have experienced at different stages of the research execution, such as empathy, loneliness, curiosity, sadness, frustration, joy, boredom, and apprehension, which were even sometimes accompanied by physiological or behavioral phenomena (Blee, 1988; Chong, 2008; Dickson-Swift, James, Kippen, \& Liamputtong, 2009; Haynes, 2006; Rager, 2005). Hence, any discussion of emotions in the context of qualitative research must include not only the research subjects or participants, but also the researchers themselves. This paper's point of departure is, therefore, that part of the labor of qualitative researchers is emotional labor, which refers to the effort a person invests in expressing or coping with his or her emotions so as to achieve objectives pertaining to his or her work:

Emotional labor means the management of feeling to create a publicly observable facial and bodily display; emotional labor is sold for wage and therefore has exchange value. (Hochschild, 1983, p. 7)

It is important to emphasize, though, that this assertion does not imply that quantitative researchers do not experience any emotions during the course of their research work.

This definition applies to many occupations, and, as we will discuss here, it also applies to research work in general and to qualitative research in particular. In her book dedicated to the field researcher's "self", Coffey (1999) succeeded in expressing the essence of the emotional labor of qualitative researchers:

We can and do feel joy, pain, hurt, excitement, anger, love, confusion, satisfaction, loss, happiness and sadness. Emotional connectedness to the processes and practices of fieldwork, to analysis and writing, is normal and appropriate. It should not be denied, nor stifled. It should be acknowledged, reflected upon, and even seen as a fundamental feature of well-executed research. Having no emotional connection to the research endeavour, setting or people is indicative of a poorly executed project. (p. 158)

This approach, according to which research work is not merely intellectual labor but also emotional labor, is reflected in various studies (e.g., Coffey, 1999; Gilbert, 2001). These researchers claimed that by adopting this approach it is possible to exploit many more means that are at the researcher's disposal and enrich the data gathering and analysis processes (Blee, 1988; Haynes, 2006; Keegan, 2006). These and other researchers contested the common assertion that mixing 
feelings into research "contaminates" research results due to lack of objectivity. They claimed that it is justified to perceive the emotions and thoughts of researchers as two inseparable parts, and that emotions must constitute a key factor in qualitative research:

We must also challenge the dominance of the western philosophical tradition that judges emotions to be the anathema to academic research ... We argue, supported by our findings ... that the theory of emotion is relevant to the work undertaken by qualitative researchers. (Dickson-Swift et al., 2009, p. 64)

Gilbert (2001) supported this viewpoint, saying that qualitative researchers no longer perceive themselves as objective spectators who are only documenting the narratives of others and reporting on them, but that they are aware that the way in which they experience reality is captured through different lenses, whereby one of them is the emotions of the researcher him or herself. Hochschild (1983), too, backed this view of objectivity. She claimed that we need emotions in order to determine what is objective and what is not:

The word objective, according to the Random House Dictionary, means "free from personal feelings". Yet ironically, we need feeling in order to reflect on the external or "objective" world. (p. 31)

In many cases, the study of emotions is conducted as a satellite research of some other research (Blee, 1998; Chong, 2008; Rager, 2005). In other words, interest in the emotional labor of researchers develops during the course of another research, not necessarily intentionally, and is studied as a secondary topic to the topic of the research in which the interest in emotions originated. One of the few studies, whose declared objective was to study researchers' emotions, was that of Dickson-Swift et al. (2009) who studied the emotional labor performed by qualitative researchers in the course of their work. The research was conducted according to the qualitative approach and included the construction of a grounded theory. In the course of this research, Dickson-Swift and her colleagues interviewed 30 researchers who were conducting research dealing with sensitive health-related topics. Based on the data analysis, the researchers determined that qualitative researchers did indeed experience emotional labor during the execution of their research, and they presented some emotional and physiological phenomena experienced by the researchersinterviewees, such as estrangement from friends and family members, sleeping apart from their spouses, experiencing hot flashes and redness in the face during the interview, and a feeling of suffocation.

Other researchers, such as Haynes (2006), Rager (2005), and Rosenblatt (2001), declared explicitly that their involvement in qualitative research changed their attitude towards themselves and other in all areas of life:

The field research experiences and my experiences interviewing individuals and families about heavy things in their lives have changed me as a human in relationship to other humans, have changed how I view myself and others, how I am a faculty member, community member, and a family member, and changed who my friends are. (Rosenblatt, 2001, p. 123)

Based on research results and personal experience, some researchers recommend that in certain research areas researchers be trained to cope with the emotional aspect of the research work and, in addition, be provided with professional, emotional support throughout the course of the research (Dickson-Swift et al., 2009; Rager, 2005; Seear \& McLean, 2008). In this spirit, Lalor, Begley, and Devane (2006) recommended including the entire research team in the emotional preparation for the conducting of research on sensitive topics. Lalor's doctoral research team (Lalor et al., 2006), for example, included her supervisor and several secretaries who transcribed the interviews held in the course of the research. A follow-up study performed on the doctoral research revealed that the entire team had experienced emotional labor. 
Thus, over the past decade, the topic "The emotional labor of qualitative researchers in social sciences" has begun to attract interest and gain significance. One piece of evidence of this trend is the committee appointed at Cardiff University (Britain) to examine the emotional risks that qualitative researchers cope with (Bloor, Fincham, \& Sampson, 2007). In the framework of the committee's work, data were gathered through interviews, focus groups, and self-reports by qualitative researchers from Britain, the US, Australia, and Europe. The committee members divided the risks experienced by the researchers into four categories: physical risks, emotional risks (the largest category), institutional risks, and gender-related risks. According to the committee reports and according to literature on the subject, researchers that deal with social topics, such as sexual assault and children at risk, or with health-related topics, such as cancer and substance and alcohol abuse, are especially exposed to emotional risk. The committee also concluded that in an attempt to keep safe the research subjects or participants, the researchers fail to protect themselves:

The literature on emotional risks suggests that, in the course of the very proper concern of researchers to protect research participants from harm, researchers have neglected to protect themselves. (Bloor et al., 2007, p. 3).

In summary, it can be said that according to the literature, the execution of qualitative research in social sciences involves the researcher's emotional labor and even exposes the researcher to possible harm. In light of this observation, according to which even experienced researchers cope with emotion management during the course of their research work, one of the issues that warrants discussion is the emotional experience of inexperienced researchers, such as doctoral students. In what follows, we will therefore discuss the emotional labor of doctoral students.

\section{Why is it Important to Study the Emotional Labor of Doctoral Students?}

According to Many, Dayagi, and Hativa (2009, p. 24), "It is important to learn about the experiences of the doctoral students on their journey to obtain the degree so as to enhance and streamline the process of studying towards the doctoral degree and promote it as a positive experience in the eyes of those experiencing it." We support this viewpoint, and particularly that one way of enhancing and streamlining the doctoral studies period is to acknowledge the emotional labor of doctoral students in general and of those conducting qualitative research in particular.

Naturally, the following question is asked: Why, in the first place, should we focus on the emotional labor of doctoral students? To answer this it suffices to examine the name given to the Ph.D. student - doctoral student. The name is derived from the word doctorate which in Greek means "faith in..." (Traford \& Leshem, 2008), implying a strong connection to the emotional realm.

In what follows we present five additional reasons that justify the conducting of research that deals with the emotional labor of doctoral students and, especially, of those involved in qualitative research. The first two reasons refer to the selection of the research topic and paradigm. The discussion of these choices from an emotional perspective raises questions such as to what extent does the emotional connection of the researcher in general and of the doctoral student, in particular, to the research topic and method contribute to the scientific work? The three other reasons address the interactions and relationships between the doctoral students and their environment supervisor, academic colleagues, and other, extra-academic entities.

Before presenting the aforementioned reasons, it is important to note, first, that it is certainly possible that some doctoral students experience no emotional labor during the execution of their research and, second, that undoubtedly not all five reasons apply to all doctoral students. 


\section{Selecting a Research Topic}

One of the most significant issues in a doctoral dissertation is the selection of the research topic. Nevertheless, this selection must be made at a relatively early stage of the studies, when the significance of the selection may not always be clear to the student. At the same time, it seems that those who have already completed the journey understand well the significance and importance of this choice. It seems that this also explains why a quick Google search, using the words "topic selection" and "doctorate", yields thousands of hits. After browsing through several dozens of such sites, a one-sentence summary of one of the main messages they convey emerges, namely, that doctoral students will do well to choose topic they are interested in (some even use the word love; e.g., "Find a topic you love", Brause, 2000, p. 30). Clearly, this act of selection is in part emotional.

Wolstenholme (2008), for instance, candidly declared that she chose her research topic (Inclusive Policy and Practices in Special Education) out of personal considerations, emotional considerations (as a mother of two special-needs children), and professional considerations (as a senior special education teacher). This indeed makes sense; after all, this choice of topic must spark interest and motivate the researcher to pursue the research for several years. In this spirit, Maxwell (2004) differentiated between three possible goals in conducting scientific research, namely, personal, practical, and intellectual, whereby he relates the personal goals to motivation and emotional motives:

It is useful to distinguish among three different kinds of goals for doing a study: personal goal, practical goals, and intellectual (or scholarly) goals. Personal goals are things that motivate you to do study, but are not necessarily important to others... they may also include deeply rooted individual desires and needs that bear little relationship to your 'official' reasons for doing the study. (p. 16)

Moreover, Lofland and Lofland (1995), as well as Dickson-Swift et al. (2009), tied the research topic to problematic issue in the researcher's personal life:

It is often said among sociologists that, as sociologists, we 'make problematic' in our research matters that are problematic in our lives". (Lofland \& Lofland, 1995 in Coffey, 1999, p. 6)

Thus, the importance of studying the emotional labor of the doctoral student is attributed to the research topic, since it will accompany the doctoral student for several years. In many cases, the research topic is connected to the doctoral student's inner-emotional world, whether it arouses the student's interest and motivation or pertains also to personal needs (or even personal problems or difficulties) that the doctoral student wishes to examine in depth in the framework of his or her research.

\section{Choosing the Research Paradigm}

According to the research literature, the research paradigm is selected in a rational manner and is, in fact, dictated by the research objective and research questions (Coffey \& Atkinson, 1996; Denzin \& Lincolnm, 2000). Nevertheless, it seems that, in reality, this process does not always take place and that the paradigm selection process often involves emotions as well.

For instance, in a limited study performed by the first author as part of a seminar paper on perceptions of doctoral students regarding significant factors in their doctoral theses, most students interviewed reported that they had chosen the qualitative research method since it enabled them to present their outlook, investigate the doctoral topic in depth, examine the causes of the observed phenomenon (rather than just report on results), present the opinions of the research participants, and maintain direct communication with the participants. Some even tied the choice of research 
method to the researcher's personal character traits. It is especially interesting to note that several doctoral students, particularly in certain specialized areas in which qualitative research is not customarily applied, explicitly stated that although their personal preference was qualitative research, the norms of the research community within which they operate caused them to adapt themselves and their personal credo so as to be more conventional and ultimately led them to conduct quantitative research.

Thus, the significance of studying the emotional labor of doctoral students also stems from the need to understand their reasoning in selecting the research paradigm, which like the research topic, will accompany the student for several years.

\section{Relationship between Doctoral Students and Their Supervisors}

In addition to choosing the research topic and paradigm, a doctoral student must also select a supervisor who will accompany him or her throughout the doctoral research. Choosing a supervisor, however, unlike choosing the research topic or paradigm, is mutual; not only does the student choose the supervisor, but the supervisor must also agree to supervise the student. This mutual selection leads to the formation of a professional and significant relationship for the doctoral student, due to the many facets of academic supervision, such as active guidance in the execution of the research and in choosing academic study courses, assisting research students in their professional, academic development, guidance on issues that pertain to the organizational culture of the university and the discipline, assistance in obtaining financial resources, and more (Many et al., 2008).

Golde (2005) reviewed the extensive literature on the reasons for graduate student attrition and, among other things, states that the supervisor is attributed great importance in the socialization process of doctoral students with respect to the various aspects of the academic world. The supervisor acts as a role model in the imparting of acceptable behavior, standards, and norms within the academic unit, as an agent of the knowledge discipline, and as the primary agent of the entire study process. This relationship is clearly asymmetric, since the student depends in many ways on the supervisor during the entire doctorate period and occasionally even after the completion of student's studies. Thus, it comes as no surprise that the relations between supervisors and students manifest also with respect to the drop-out of doctoral students during their studies, which is one of the more researched topics in the context of doctoral students. Golde found that poor studentsupervisor compatibility is one of the main causes for the drop-out of doctoral students.

One reason for student-supervisor incompatibility may be differences in expectations they have from one another. According to Gardner (2008), such differences may stem from the fact that during the doctorate period, doctoral students change their status: from students, whose tasks are dictated by their instructors, into independent researchers, who determine their own agenda, tasks, and time schedule. This process may cause frustration and difficulty for some doctoral students, who might have different expectations from the supervision process.

A survey conducted at Tel-Aviv University (Many et al., 2009) on the experiences of doctoral students reveals several findings about doctoral supervisors in general and about the relationship between doctoral students and their supervisors in particular. In addition to the difficulties students experience when seeking a supervisor, it seems that the students are aware of the importance of the supervisor's personality. Students listed the supervisor's character traits as being second in importance on the list of considerations for choosing a supervisor, outranking the supervisor's academic reputation as a consideration. Gardner (2008), too, noted that in her research students reported that their meetings with their supervisors and the support they received from them were frequently more significant than the supervisor's expertise in the knowledge discipline and that, had they not had such close relationships, their study track would have been more diffi- 
cult. These data support narratives concerning the relationships between supervisors and doctoral students that can be heard around any university and are voiced on various doctoral student forums (see, for example, the Israeli forum of authors of thesis and dissertations). It should be mentioned, that in the above-mentioned survey (Many et al., 2009), the majority of respondents $(81 \%)$ testified to a high level of overall satisfaction with their supervisors, and the comments containing criticism of the supervisors referred specifically to the lack of personal attention.

Following all of the above, we thought that student-supervisor relationships should be mentioned as one of the more important reasons for conducting research on the emotional labor of doctoral students. Although this topic has been studied in the past (e.g., Gardner, 2008; Golde, 2005), we are of the opinion, in light of its importance, that it would be appropriate to study this relationship also in the context of the emotional labor of doctoral students and to illuminate the topic from yet another perspective.

\section{Relationships between Doctoral Students and Their Colleagues}

Weidman, Twale and Stein (2001) defined graduate student socialization as "the process through which individuals gain the knowledge, skills, and values necessary for successful entry into a professional career requiring an advanced level of specialized knowledge and skills" (p. 4). Socialization of doctoral students in academia takes place mainly through their interaction and experience within the research group or groups to which they belong (Mendoza, 2007). Such socialization has many aspects, such as acquaintance with the university's internal procedures and with the knowledge discipline, the exchange of technical and content information among doctoral students (see, for example, Azuma, 2003), and the formation of support groups (Hadjioannou, Shelton, Fu, \& Dhanarattigannon, 2007; Rager, 2005; Wolstenholme, 2008). We mention that such socialization is a major issue for the large numbers of doctoral students who study part-time (and sometimes at a distance).

According to Lovitts (2005 in Terrell, Snyder, \& Dringus, 2009), the micro-environment, which includes colleagues and faculty members, is the second factor in importance to influence the successful completion of doctoral theses by doctoral students. Despite the advantages inherent in such relations, it seems that they may also wear the doctoral students out:

One cause of attrition is program culture. An important component of program culture is the messages communicated between organizational veterans and newcomers. (Lovitts, 2001, in Sweitzer, 2009, p.29)

Doctoral student forums, among other sources, can teach us about the importance, the essence, and the scope of the relationships between doctoral students. The information they contain extends over many areas, ranging from technical information on the use of MS Word, through practical advice on the purchasing one computer or another and the provision of emotional support to one another, to in-depth discussions on supervisor-supervisee relations. It seems reasonable to assume that such online forums are but a mirror of real relationships formed on the campuses themselves.

Naturally, each student experiences this relationship differently. This is true not only for students studying in different universities, but also for student studying at the same university but in different faculties. Lovitts (2000) presented a theory correlating graduate students' academic and social integration with the structure of the discipline. She claims that the structure of the discipline dictates the kind and extent of interactions that take place between the students:

Intellectual structure of the discipline shapes opportunities for academic and social integration across departments within that discipline by structuring the nature of academic tasks 
and the frequency of academic interactions as well as the social relationships that develop out of task-related interactions. (Lovitts, 2000)

Thus, while natural science students in many cases spend long hours in the laboratory, working side by side with others in their research groups, research in the social sciences, in which topics are studied mainly using qualitative research, is characterized by individual work. As a result, there is less social and academic interaction between students in the social sciences (Bowen \& Rudenstine, 1992; Wilson, 1965, in Lovitts, 2000).

In an attempt to overcome this lack of interaction, research groups are created for doctoral students with common interests such as methodology (e.g., qualitative research) or content (e.g., managerial aspects of high schools). Gardner and Barnes (2007) studied another way of social integration that involved graduate students, in general, and doctoral students, in particular, in activities such as organizing conferences, volunteer work, or any other activity in which other students and faculty members take part. According to the research findings, such involvement is an integral part of the socialization process of graduate students in their future occupation (if it be) in the academia.

It is evident that the professional relationships between doctoral students and their colleagues are important during the doctoral research period (and probably also after that), and that such relationships may serve as a source of support, attrition, professional development, and so on. Since these relationships may add to the doctoral student's emotional load, or detract from it, we attribute great importance to the investigation of such relations as part of the emotional labor of doctoral students.

\section{Doctoral Students' Relationships Outside of Academia}

Since doctoral studies are the final stage of the formal academic study track, some doctoral students have families and extensive social obligations, which, on the one hand, demand their attention, but on the other hand, provide them with a non-professional, but nonetheless very valuable, support network. Following are several examples that reflect the importance of such support during the execution of a qualitative doctoral research.

While reading her researcher's diary during the writing process of her thesis, Rager (2005), who studied the self-directed learning of breast cancer patients, noted that during the data gathering stage she had experienced a variety of aches and different physical symptoms that resembled those reported by her interviewees. She listed several things that helped her get through that difficult time and, among others, she mentioned her family:

My husband, daughters, and friends helped to fill that need in my case. They ensured that life was more than just a dissertation and a job during that time frame. (p. 26)

Haynes (2006) described, with admirable candidness, the changes she made in her personal life when she embarked on her doctoral studies in order to be more available for her children, the changes she made in her personal life during her studies, and the satisfaction and support she currently receives from her new family.

Hadjioannou et al. (2007) reported on a social-professional support network that they created for themselves with colleagues from within the academia and from outside of it, since the majority of the group members were foreign, female students. The formation of such a group, in the absence of familial support networks, highlights the importance of the latter.

Additional examples of the importance of extra-academic social relationships during the doctoral period are presented by Coffey (1999) in her book, in which she compiled numerous examples from ethnographic researches in which the researchers are physically situated far from any famil- 
iar social network and, during their academic or research activity, form social relationships in addition to professional connections.

Thus, we see that many researchers addressed their emotional labor during the execution of qualitative research, a burden that manifests itself in emotional and even physical phenomena. Coping with such phenomena is facilitated by social relationships, a fact that emphasizes, again, the importance of studying the emotional labor of doctoral students, in this case in the context of social relationships and their role in the process of conducting research.

\section{Can the Topic "The Emotional Labor of Doctoral Students" Constitute in Itself a Topic for a Doctoral Dissertation?}

Studies in which doctoral students are the research population focus on a variety of subjects: causes of doctoral student drop-out (Ali \& Kohun, 2006; Lovitts, 2000, 2001), motivation factors (Golde, 2005), effective classroom learning and teaching methods in graduate studies (Many et al., 2009), the connection between graduate studies and market demands (Mendoza, 2007), the socialization process with academic life (Gardner, 2008; Gardner \& Barnes, 2007; Sweitzer, 2009), and so on. Our extensive search, however, did not yield even a single study, among all researches dealing with the doctoral student population, that focused on the emotional labor of doctoral students.

In our attempts to explain this phenomenon, we came up with the following five possible obstacles for conducting a doctoral dissertation on this subject. The first two analyze the situation from the viewpoint of those conducting the research - the doctoral student and the supervisor; the other three difficulties refer to the perspective of the research participants - other doctoral students and supervisors.

\section{Researchers' Perspective}

\section{The doctoral student studying emotional labor}

In addition to the challenges and difficulties that face any doctoral student, doctoral students studying the emotional labor of other doctoral students will encounter some additional, unique difficulties that stem from the specific research topic and research population.

The research topic - the emotional labor of doctoral students - puts the doctoral student in a defensive position vis-à-vis the view according to which it is unscientific to attribute feelings to a research process and that this might even be detrimental to science. In other words, such doctoral students will be more exposed to criticism from the academic community and might even risk having a tougher time defending their thesis. In addition, if the research population includes supervisors from the doctoral student's field of expertise, the doctoral student might find him or herself in an unpleasant situation if any of them are criticized, even if such research is conducted, as customary according to research ethics, anonymously.

\section{The supervisor supervising doctoral research on emotional labor}

Like the doctoral students, supervisors of doctoral research on the emotional labor of doctoral students expose themselves to criticism from those who do not view feelings as part of the scientific research process. In addition, here too, if the research population comes from the supervisor's area of research, revealing of various aspects related to student-supervisor relations might spark tension between members of the scientific community. 


\section{Research Participants' Perspective}

Research participants in any research studying the emotional labor of doctoral students will naturally be students conducting doctoral research. Additional groups may also participate in such research, such as supervisors and family members. For the purposes of the present discussion, we assume that the research population is composed of doctoral students and supervisors and present the difficulties that may arise from their perspective when conducting doctoral research on the emotional labor of doctoral students.

\section{The perspective of doctoral students participating in the research}

Apprehensions of doctoral students participating in the research about describing their feelings, in general, and their relationships with their supervisors, in particular. As mentioned above, the first author conducted a limited study, in the framework of an advanced course on qualitative research methods, that examined the perceptions of doctoral students regarding significant factors in their doctoral theses. Interviews were held with several doctoral students from her own department, as well as from other departments. All of the interviewees had a social relationship with the author and they all willingly agreed to be interviewed. Nevertheless, during these interviews, apprehensions arose about speaking candidly on several issues, particularly with respect to their relationships with their supervisors. This study cannot, of course, serve as a basis for any generalization, but it can certainly indicate a problem that might arise during data gathering in the context of the emotional labor of doctoral students in general and the relationships between doctoral students and their supervisors in particular, especially in cases in which such relations are problematic. This difficulty in gathering data in this context is significant in light of the fact that doctoral student-supervisor relations were mentioned above as one of the reasons for studying the emotional labor of doctoral students.

The existence of the doctoral student in the midst of a research process. The doctoral process is a complex, intensive, emotionally loaded, depleting, challenging, and interesting process, during which the doctoral student experiences a wide range of situations, challenges, and emotions. In addition, research, when conducted according to the qualitative approach, is being formed and designed during the course of its execution in parallel to the professional development of the researcher as constituting the primary research tool in this activity. This approach is supported by Coffey (1999), who claimed that the "self" is not complete and rounded, but rather complex, segmented, and subject to changes and influences both from within and from outside:

Selves and identities are fragmented and connected, open to shifts and negotiations. They are ambiguous, the outcome of culturally available and defined interactions, actions, meanings and values. The self is not so much complete and rounded, as partial and multiple. (p. 35)

If we apply Coffey's (1999) approach to the selves of doctoral students, who are in the midst of a professional shaping process and are interviewed as part of the doctoral research on emotional labor of doctoral students, and if we accept the opinion voiced by Schön $(1983,1987)$ regarding the significance of integrating a reflective process into the practice of practitioners, questions will naturally arise, such as: Are in-depth reflective processes that are guided by a colleague who is partner to a similar process (conducting doctoral research) desirable for doctoral students participating in the research? And, whose needs are ultimately served by the reflection process, those of the doctoral student-researcher or those of the doctoral student-interviewee?

\section{The perspective of supervisors of research participants}

In this context, we refer to the consent supervisors give to their doctoral students to participate in the research and to the possibility that they will not give such consent to participate. 
There are several reasons why supervisors might not give their doctoral students consent to participate in a research that deals with the emotional labor of doctoral students. First, supervisors may doubt the contribution of such participation to the research of their doctoral students, which has no relevance to the topic of the doctoral dissertation that deals with emotional labor. Second, by giving such consent to participate in such research, the supervisor exposes him or herself to criticism, which, even if such criticism already exists as a kind of local folklore, when expressed as part of a research (even if anonymously), might attract different attention. Such criticism might also affect the evaluation of academic faculty members who do not usually receive feedback on this aspect of their academic work. In this context, Many et al. (2009) noted that "the supervision of thesis works, which is a central teaching activity at universities, has almost never been studied ... Supervisors receive no detailed or direct feedback and evaluation about the quality of their supervision from the students they supervise" (p. 24). Questions that arise, in the context of the present paper, include: Are supervisors interested in receiving such feedback? And, will they want to receive such feedback in the framework of a doctoral research on the emotional labor of doctoral students?

\section{Conclusion}

The objective of this paper was to raise for discussion the issue of the emotional labor of doctoral students while conducting their doctoral research, which is a private case of a broader topic - the emotional labor of researchers during their research work. According to our literature review, most of the research done in connection with the emotional labor of researchers focuses on specific cases of female researchers in the social sciences who were engaged in qualitative research. In addition, in most cases studies dealing with the emotional labor of researchers were "satellite studies" of other researches that were at the heart of the researchers' attention (usually doctoral theses). Further, it is important to note that most of these studies were published several years after the doctoral theses themselves were completed, which naturally makes one wonder about the time of their publication. This phenomenon can possibly be explained, at least in part, by some of the same reasons given in response to the second question: Can the topic "The emotional labor of doctoral students" constitute in itself a topic for a doctoral dissertation? But the explanation, in our opinion, is possibly much simpler: we suggest that such a thesis has not yet been written since in order to study the emotional labor of doctoral students, the doctoral student must experience such labor and be aware of its place in the research process; it is reasonable to assume that this stage can be attained only after performing part of a doctoral work, which of course focuses on a topic that was chosen at the onset of the doctoral process.

We conclude by noting that similar to the emotional labor of researchers, the emotional labor of doctoral students also constitutes an extensive research area that has not yet been sufficiently studied. We found no theory in the literature that unites all that is known so far about the emotional labor of researchers in general and of doctoral students in particular. We estimate that such a theory would enrich the existing knowledge on the execution of (qualitative) research in general and the improvement of service for doctoral students in particular. Such research might also serve as a setting for calls that have been heard recently to acknowledge the emotional labor of researchers, and to prepare researchers and other research team members for its execution (Dickson-Swift et al., 2009; Haynes, 2006; Jarzabkowski, 2001; Ranger, 2005; Seear \& McLean, 2008). 


\section{References}

Ali, A., \& Kohun, F. (2006). Dealing with isolation feelings at IS doctoral programs. International Journal of Doctoral Studies, 1, 21-33. Retrieved from http://www.ijds.org/Volume1/IJDSv1p021-033Ali13.pdf

Atkinson, P., Delamont, S., \& Parry, O. (2000). The doctoral experience. Routledge, UK.

Azuma, R. T. (2003). "So long, and thanks for the Ph.D.!" a.k.a. "Everything I wanted to know about C.S. graduate school at the beginning but didn't learn until later." Retrieved February 20, 2011, from http://www.cs.unc.edu/ azuma/hitch4.html

Blee, K. M. (1998). White-knuckle research: Emotional dynamics in fieldwork with racist activists. Qualitive Sociology, 21(4), 381-399.

Bloor, M., Fincham, B., \& Sampson, H. (2007). Quality (NCRM) commissioned inquiry into the risk of well-being of researchers in qualitative research. Retrieved November 1, 2009, from http://www.cardiff.ac.uk/socsi/qualiti/cireport.pdf

Bowen, W. G., \& Rudenstine, N. L. (1992). In pursuit of the Ph.D. Princeton, NJ: Princeton University Press.

Brause, R. S. (2000). Writing your doctoral dissertation: Invisible rules for success. Routledge.

Chong, K. H. (2008). Coping with conflict, confronting resistance: Fieldwork emotions and identity management in a South Korean evangelical community. Qualitative Sociology, 31(4), 369-390.

Coffey, A. (1999). The ethnographic self. SAGE Publications.

Coffey, A., \& Atkinson, P. (1996). Making sense of qualitative data. Sage Publications.

Denzin, N. K., \& Lincolnm, Y. S. (2000). Handbook of qualitative research (2nd ed.). Sage Publications.

Dickson-Swift, V., James, E. L., Kippen, S., \& Liamputtong, P. (2009). Researching sensitive topics: Qualitative research as emotion work. Qualitative Research, 9(1), 61-79.

Gardner, S. K. (2008). "What's too much and what's too little?": The process of becoming an independent researcher in doctoral education. Journal of Higher Education, 79(3), 326-350.

Gardner, S. K., \& Barnes, B. J. (2007). Graduate student involvement: Socialization for the professional role. Journal of College Student Development,48(4), 369-387.

Gilbert, K. R. (2001). Introduction: Why are we interested in emotions? In K. R. Gilbert (Ed.), The emotional nature of qualitative research (pp. 3-15). Boca Raton, FL: CRC Press LLC.

Golde, C. M. (2005). The role of the department and discipline in doctoral student attrition: Lessons from four departments. Journal of Higher Education, 76(6), 669-700.

Hadjioannou, X., Shelton, N. R., Fu, D., \& Dhanarattigannon, J. (2007). The road to a doctoral degree: Cotravelers through a perilous passage. College Student Journal, 41(1), 160-177.

Haynes, K. (2006). A therapeutic journey? Reflections on the effects of research on researcher and participants. Qualitative Research in Organizations and Management: An International Journal, 1(3), 204-221.

Hochschild, A. R. (1983). The managed heart. Berkeley: University of California Press.

Jarzabkowski, L. (2001). Emotional labour in educational research. Queensland Journal of Educational Research, 17(2), 123-137.

Keegan, S. (2006). Emerging from the cocoon of science. The Psychologist, 19(11), 668-671 .

Lalor, J. G., Begley, C. M., \& Devane, D. D. (2006). Exploring painful experiences: Impact of emotional narratives on members of a qualitive research team. Journal of Advanced Nursing, 56(6), 607-616.

Lofland, J., \& Lofland, L. H. (1995). Analyzing social settings: A guide to qualitative observation and analysis (3rd ed.). Belmont, CA: Wadsworth. 
Lovitts, B. E. (2000). Context and attrition. Making Strides 2(3). Retrieved December 11, 2009, from http://ehrweb.aaas.org/mge/Archives/6/context.html

Lovitts, B. E. (2001). Leaving the ivory tower: The causes and consequences of departure from doctoral study (1st ed.). New York: Rowman and Littlefield Publishers, Inc.

Lovitts, B. E. (2005). Being a good course-taker is not enough: A theoretical perspective on the transition to independent research. Studies in Higher Education, 30(2), 137-154.

Lucas, K. B., \& Lidstone, J. G. (2000). Ethical issues in teaching about research ethics. Evaluation and Research in Ethics, 14, 53-64.

Many, A., Dayagi, R., \& Hativa, N. (2009). Experiences of doctoral students on their road to graduation. $A l$ Hagova, 8, 24-28. [in Hebrew].

Maxwell, J. A. (2004). Qualitative research design: An interactive approach (2nd ed.). Thousand Oaks, CA: Sage .

Mendoza, P. (2007). Academic capitalism and doctoral student socialization: A case study. Journal of Higher Education, 78(1), 71-96.

Rager, K. (2005). Self-care and the qualitative researcher: When collecting data can break your heart. Educational Researcher, 34, 23-27.

Rosenblatt, P. C. (2001). Qualitative research as a spiritual experience. In K. R. Gilbert (Ed.), The emotional nature of qualitative research (pp. 111-129). Boca Raton, FL: CRC Press LLC.

Schön, D. A. (1983). The reflectivep practitioner. Basicbooks.

Schön, D. A. (1987). Educating the reflective practitioner: Towards a new design for teaching and learning in the profession. San Francisco: Jossey-Bass.

Seear, K., \& McLean, K. (2008). Breaking the silence: The role of emotional labour in qualitative research. Retrieved December 1, 2009, from www.tasa.org.au/conferencepapers08/Sociology\%20as\%20Discipline/Seear, $\% 20$ Kate, $\% 20$ Session $\% 2$ 015\%20PDF.pdf

Sweitzer, V. (2009). Towards a theory of doctoral student professional identity development: A developmental networks approach (Report). Journal of Higher Education, 80(1), 1-33.

Terrell, S. R., Snyder, M. M., \& Dringus, L. P. (2009). The development, validation, and application of the Doctoral Student Connectedness Scale. The Internet and Higher Education, 12(2), 112-116.

Traford, V., \& Leshem, S. (2008). Stepping stones to achieving your doctorate. Open University Press.

Weidman, J. C., Twale, D. J., \& Stein, E. L. (2001). Socialization of graduate and professional students in higher education: A perilous passage. ASHE-ERIC Higher Education Report 28, no. 3. Washington, DC: Association for the Study of Higher Education.

Wilson, K. M. (1965). Of time and the doctorate: Report of an inquiry into the duration of doctoral study. Atlanta, GA: Southern Regional Education Board.

Wolstenholme, C. (2008). Experience of completing a PhD: A student's perspective. Support for Learning, 23(4), 208-211. 


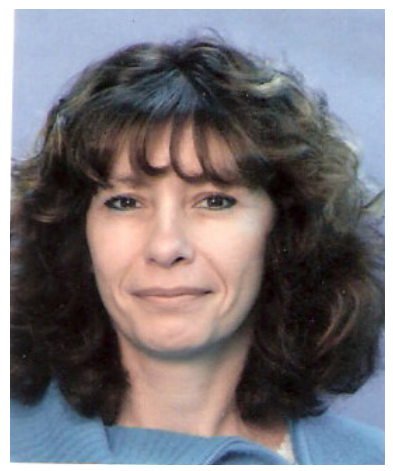

\section{Biographies}

Liora Nutov is a PhD student at the Technion's Department of Education in Technology and Science, a lecturer in Gordon College of Education and in Oranim College of Education, and she has 20 years of experience as a Mathematics educator and a homeroom teacher. Her accumulative experience as a homeroom teacher has been encapsulated in her book "Educator LTD" published in 2006. She holds a Bachelor degree in Applied Mathematics, and an M.A. in Mathematics Education from the Technion. Liora's research interests include educational administration, researchers' emotions, teaching and learning of qualitative research methods, and mathematical education.

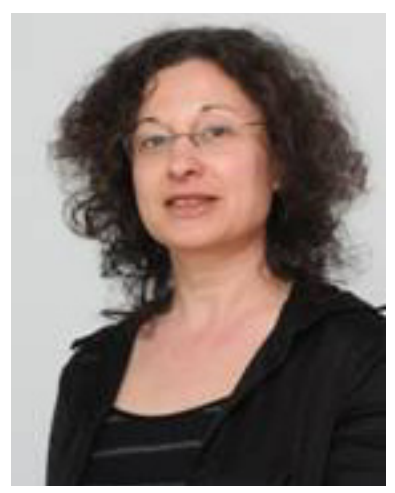

Orit Hazzan is an Associate Professor and head of the Department of Education in Technology and Science of the Technion - Israel Institute of Technology. Her research interests include computer science and software engineering education, teaching and learning qualitative research methods, and change management. She wrote three books: $\mathrm{Hu}$ man Aspects of Software Engineering (2004, Charles River Media), Agile Software Engineering (2008, Springer) and Guide to Computer Science Teaching: An Activity-Based Approach (2011, Springer). She published about 100 articles in referred journals and conference proceedings. She has supervised 8 doctoral students and 8 Masters students. Between 2006 and 2008 she was the vise dean of undergraduate studies of the Technion. 